\title{
Smoking abstinence 1 year after acute coronary syndrome: follow-up from a randomized controlled trial of varenicline in patients admitted to hospital
}

\author{
Sarah B. Windle MPH, Payam Dehghani MD, Nathalie Roy MD, Wayne Old MD, François R. Grondin MD, \\ Iqbal Bata MD, Ayman Iskander MD, Claude Lauzon MD, Nalin Srivastava MD, Adam Clarke MD, \\ Daniel Cassavar MD, Danielle Dion MD, Herbert Haught MD, Shamir R. Mehta MD, Jean-François Baril MD, \\ Charles Lambert MD, Mina Madan MD, Beth L. Abramson MD MSc, Mark J. Eisenberg MD MPH; for the EVITA \\ Investigators*
}

Cite as: CMAJ 2018 March 26;190:E347-54. doi: 10.1503/cmaj.170377

See related article at www.cmaj.ca/lookup/doi/10.1503/cmaj.180125

\section{ABSTRACT \\ BACKGROUND: Patients who continue to smoke after acute coronary syndrome are at increased risk of reinfarction and death. We previously found use of varen- icline to increase abstinence 24 weeks after acute coronary syndrome; here we report results through 52 weeks.}

METHODS: The EVITA trial was a multicentre, double-blind, randomized, placebo-controlled trial of varenicline for smoking cessation in patients admitted to hospital with acute coronary syndrome. Participants were randomly assigned (1:1) to receive varenicline or placebo for 12 weeks, in conjunction with low-intensity counselling. Smoking abstinence was assessed via 7-day recall, with biochemical validation using exhaled carbon monoxide. Participants lost to follow-up or withdrawn were assumed to have returned to smoking.

RESULTS: Among the 302 participants, abstinence declined over the course of the trial, with $34.4 \%$ abstinent 52 weeks after acute coronary syndrome. Compared with placebo, point estimates suggest use of varenicline increased point-prevalence abstinence (39.9\% v. $29.1 \%$, difference $10.7 \%, 95 \%$ confidence interval [Cl] $0.01 \%$ to $21.44 \%$; number needed to treat 10 ), continuous abstinence $(31.1 \%$ v. $21.2 \%$, difference $9.9 \%, 95 \% \mathrm{Cl}-0.01 \%$ to $19.8 \%$ ) and reduction in daily cigarette smoking by $50 \%$ or greater $(57.8 \%$ v. $49.7 \%$, difference $8.1 \%, 95 \% \mathrm{Cl}-3.1 \%$ to $19.4 \%)$. Varenicline and placebo groups had similar occurrence of serious adverse events ( $24.5 \%$ v. $21.9 \%$, risk difference $2.7 \%$, 95\% $\mathrm{Cl}-7.3 \%$ to $12.6 \%$ ) and major adverse cardiovascular events ( $8.6 \%$ v. $9.3 \%$, risk difference $-0.7 \%, 95 \% \mathrm{Cl}-7.8 \%$ to $6.5 \%$ ).

INTERPRETATION: Varenicline was efficacious for smoking cessation in this high-risk patient population. However, $60 \%$ of patients who received treatment with varenicline still returned to smoking. Trial registration: ClinicalTrials. gov, no. NCT00794573 moking cessation is of critical importance for patients immediately following an acute coronary syndrome, substantially reducing negative outcomes such as reinfarction and death among successful quitters..$^{1-4}$ The acute hospital admission is a "teachable moment" in which smokers may be more receptive to information about quitting and more motivated to make a quit attempt. ${ }^{5}$ It is also a valuable opportunity to provide smokers, particularly those who may not have been in recent contact with a health care provider, with assistance in quitting and to organize longitudinal support for a quit attempt, as patients return for regular follow-up after acute coronary syndrome.

However, there is limited evidence available concerning the use of smoking cessation therapies in patients with acute cardiovascular conditions. Although the use of nicotine replacement therapies (e.g., nicotine patch and nicotine gum) is common, there is a lack of clinical trial data supporting the efficacy and safety of these therapies in patients with cardiovascular disease. ${ }^{6,7}$ 
Additionally, data from a number of trials suggest that bupropion is not efficacious in this population. ${ }^{8-10}$ Varenicline, a partial agonist of $\alpha 4 \beta 2$ nicotinic acetylcholine receptors, has been widely studied in the general population, with efficacy appearing to meet or exceed that of nicotine replacement therapies and bupropion. ${ }^{11-13}$ Along with bupropion, varenicline has been shown to increase abstinence in patients with stable cardiovascular disease; however, its efficacy in patients with acute coronary syndrome was previously unknown. ${ }^{6}$ We have recently shown that use of varenicline increases smoking abstinence 24 weeks after acute coronary syndrome. ${ }^{14}$ Here we report evidence concerning the efficacy and safety of varenicline for smoking cessation 52 weeks after acute coronary syndrome.

\section{Methods}

\section{Study design}

The Evaluation of Varenicline in Smoking Cessation for Patients Post-Acute Coronary Syndrome (EVITA) trial is a randomized, placebo-controlled trial that enrolled 302 participants across Canada and the United States. The methods of this trial have been previously described in detail. ${ }^{15}$ Enrolment took place during hospital admission for acute coronary syndrome, including myocardial infarction and unstable angina with clinically significant coronary artery disease. To be eligible, patients had to be motivated to quit and have smoked 10 or more cigarettes per day for the past year. Patients with a history of mental illness were excluded, as was standard practice for clinical trials at the time of study design, owing to concerns about serious neuropsychiatric events in individuals with pre-existing psychiatric disease taking varenicline. Those who consented to participate and met the inclusion and exclusion criteria were randomly assigned $1: 1$ to varenicline tartrate $(0.5 \mathrm{mg}$ daily for 3 days, then $0.5 \mathrm{mg}$ twice daily for 4 days, followed by $1.0 \mathrm{mg}$ for 11 weeks) or matching placebo for 12 weeks, combined with low-intensity counselling for smoking cessation and relapse prevention. Treatment was initiated in-hospital.

\section{Follow-up and end points}

Participants were followed for 52 weeks after acute coronary syndrome, with telephone calls at weeks 1, 2 and 8, and clinic visits at weeks 4, 12, 24 and 52. Self-reported smoking abstinence was biochemically validated at clinic visits using exhaled carbon monoxide (Micro 3/4 Smokerlyzer, Bedfont Scientific Ltd.). Measurement of exhaled carbon monoxide is a practical and reliable method of assessing smoking status, which correlates with the frequency and quantity of cigarettes smoked. ${ }^{16}$ Although its ability to detect nonrecent smoking ( $>8 \mathrm{~h}$ ) is limited, ${ }^{16}$ participant perception of greater efficacy may increase the validity of selfreport data. ${ }^{17}$

The prespecified primary end point was smoking abstinence at week 24 (previously reported). ${ }^{14}$ Point-prevalence abstinence was defined as self-reported abstinence in the past week (no smoking, not even a puff), with exhaled carbon monoxide levels of $10 \mathrm{ppm}$ or less. Continuous abstinence was defined as selfreported abstinence in the past week at all follow-ups since baseline, with exhaled carbon monoxide levels of $10 \mathrm{ppm}$ or less at all clinic visits. Reduction in daily cigarette consumption by $50 \%$ or greater was also assessed.

\section{Statistical analysis}

We used the intention-to-treat principle for all analyses. As in other trials of smoking cessation, our analyses assumed that participants who were lost to follow-up or withdrew returned to smoking at their baseline rate. Sensitivity analyses were conducted to examine the effect of this assumption. Participants who died were censored from analyses after death. The number needed to treat (NNT) represents the number of patients with acute coronary syndrome who needed to receive treatment with varenicline for 1 patient to be abstinent. Statistical analyses were performed using SAS software (version 9.3).

\section{Ethics approval}

This study complied with the Declaration of Helsinki; locally appointed ethics committees approved the research protocol, and informed consent was obtained from participants before enrolment.

\section{Results}

\section{Participant characteristics}

Participants enrolled in the trial ( $n=302$ ) (Figure 1) were primarily male $(75.2 \%)$ with a mean age of 55.0 (standard deviation [SD] 9.3) years, and had been smoking for the past 3-4 decades (35.9 [SD 11.6] yr). At the time of their acute coronary syndrome $(56.0 \%$ ST-segment elevation myocardial infarction, $37.8 \%$ non-ST segment elevation myocardial infarction and $6.3 \%$ unstable angina), participants were smoking a mean of 21.4 (SD 10.6) cigarettes per day. Most (80.4\%) had a score of 4 or greater on the Fagerström Test for Nicotine Dependence, indicating moderate or severe dependence on nicotine. Most had made at least 1 previous attempt to quit smoking $(81.8 \%)$ and many had another smoker living at home (41.7\%). Participant characteristics (Table 1) were well-balanced between the varenicline and placebo groups, ${ }^{14}$ with the exception of the proportion of participants with another smoker at home, which was higher in the varenicline group $(48.3 \% \mathrm{v}$. $35.1 \%$, difference $13.2 \%)$.

\section{Drug course}

The median length of hospital stay was 3 (interquartile range [IQR] 2-4) days, and the median time from admission to the first dose of study medication was 2 (IQR 1-3) days. At the conclusion of the treatment period (12 wk), most participants reported taking 2 pills per day (per the protocol): $70.5 \%$ of participants in the varenicline group compared with $82.1 \%$ of participants in the placebo group ( $p=0.07$; adherence data available for 218 participants). An additional $7.1 \%$ in the varenicline group and $2.8 \%$ in the placebo group reported taking 1 pill per day (as may be recommended to reduce adverse effects). Study personnel and participants were unaware of treatment allocation until the conclusion of the trial, with participant 


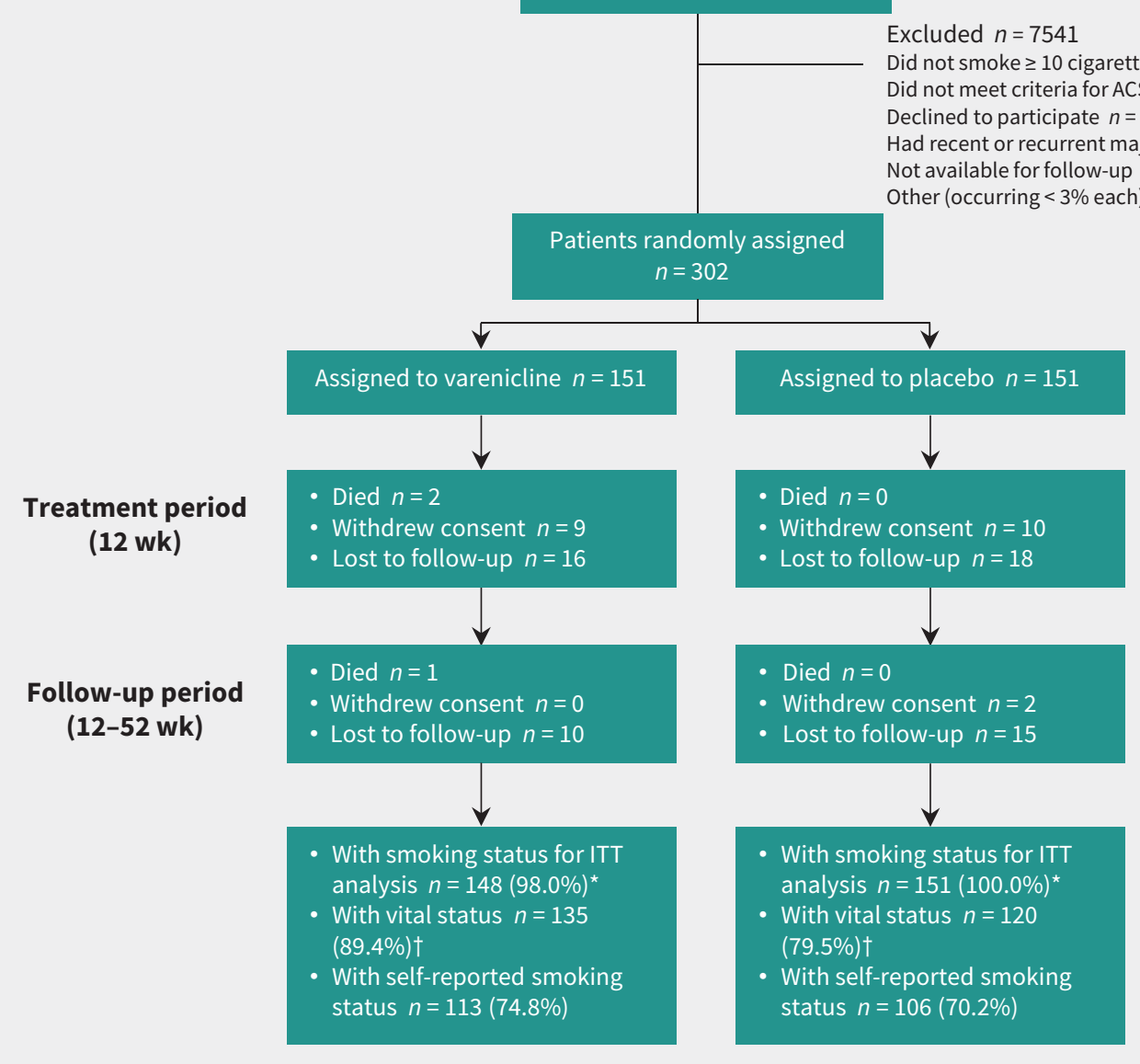

Figure 1: Randomization and follow-up of study patients. *Includes all patients except those who died. For the intention-to-treat (ITT) analysis, patients who were lost to follow-up or withdrew were assumed to have returned to smoking at their baseline rate. †In the event of loss to follow-up, vital status was obtained from chart review if possible. ACS = acute coronary syndrome.

guesses of treatment assignment no better than chance $(49.1 \%$ in the varenicline group and $48.8 \%$ in the placebo group correctly guessed their treatment assignment at week 12).

\section{Smoking cessation}

Point-prevalence smoking abstinence declined over the course of the trial (Figure 2), from a high of $58.6 \%$ of all participants at week 1 to a low of $34.4 \%$ of all participants at week 52 . There was an immediate difference in abstinence between the varenicline and placebo groups beginning at the first follow-up telephone call at week 1: $66.2 \%$ versus $51.0 \%$, respectively. The difference in point-prevalence abstinence remained significant at all followups through the end of the 12-week treatment period and 52-week follow-up (differences and 95\% confidence intervals [Cls] presented in Appendix 1, supplementary Table 1, available at www.cmaj.ca/lookup/suppl/doi:10.1503/cmaj.170377/-/DC1). A similar trend was observed for continuous abstinence, with significant differences observed between groups throughout the 12-week treatment period, although $\mathrm{Cls}$ included the null at week-24 and -52 follow-up (Appendix 1, supplementary Table 1).

Smoking abstinence and reduction data from clinic visits at weeks 4, 12, 24 and 52 are shown in Figure 3. Abstinence data at the primary end point of week 24 have been previously reported. ${ }^{14}$ At week 24 , use of varenicline was found to increase point-prevalence smoking abstinence $(47.3 \%$ v. $32.5 \%)$ and reduction in daily cigarette consumption by $50 \%$ or greater $(67.4 \%$ v. $55.6 \%)$ compared with placebo. Continuous abstinence rates were $35.8 \%$ in the varenicline group versus $25.8 \%$ in the placebo group at week 24 . At week 52, pointprevalence smoking abstinence was significantly higher in the varenicline group (39.9.\%) compared with the placebo group (29.1\%) (difference $10.7,95 \% \mathrm{Cl} 0.01 \%$ to $21.44 \%$; NNT 10 ). Rates of continuous abstinence at week 52 were $31.1 \%$ in the varenicline group versus $21.2 \%$ in the placebo group (difference 
No. $(\%)$ of participants ${ }^{\star}$

\section{Characteristic}

\section{Demographic}

Age, $y r$, mean \pm SD

Male sex

\section{Smoking}

Smoking duration, yr, mean \pm SD

Cigarettes per day at baseline, mean \pm SD

Fagerström Test for Nicotine Dependence score†

$$
\begin{aligned}
& \text { 0-3 (mild) } \\
& \text { 4-6 (moderate) } \\
& \geq 7 \text { (severe) }
\end{aligned}
$$

Other smoker(s) at home

\section{Medical history}

Hyperlipidemia

Hypertension

Diabetes

Prior use of antidepressants

Prior myocardial infarction

Prior percutaneous coronary intervention

Prior coronary artery bypass graft

Prior transient ischemic attack or cerebrovascular accident

\section{Hospital admission}

ST-segment elevation myocardial infarction

Non ST-segment elevation myocardial infarction

Unstable angina

Procedures

Cardiac catheterization

Percutaneous coronary intervention

Coronary artery bypass graft

Length of stay, $d$, median (IQR)

Time from admission to first dose of study medication, $d$, median (IQR)

Note: $\mathrm{IQR}=$ interquartile range, $\mathrm{SD}=$ standard deviation

*Unless stated otherwise.

†Score ranges between 0 and 10 .

$9.9 \%, 95 \% \mathrm{Cl}-0.01 \%$ to $19.8 \%)$. Reduction in daily cigarette consumption by $50 \%$ or greater was $57.8 \%$ in the varenicline group compared with $49.7 \%$ in the placebo group (difference $8.1 \%, 95 \% \mathrm{Cl}-3.1 \%$ to $19.4 \%)$. Among only those who continued to smoke, reduction by $50 \%$ or greater was $29.5 \%$ in the varenicline group and $29.0 \%$ in the placebo group (difference $0.5 \%, 95 \% \mathrm{Cl}-12.3 \%$ to $13.4 \%$ ).

Abstinence was biochemically validated using exhaled carbon monoxide at clinic visits. A total of $81.7 \%$ of participants self-reporting abstinence at week 52 provided biochemical validation (owing to completion of some clinic visits by telephone,

$\begin{array}{cc}\text { Varenicline } & \text { Placebo } \\ n=151 & n=151\end{array}$

$54.7 \pm 8.4$

$112(74.2)$

$35.1 \pm 11.4$

$21.9 \pm 10.9$

30 (19.9)

77 (51.0)

$43(28.5)$

$73(48.3)$

$96(63.6)$

79 (52.3)

$33(21.9)$

$16(10.6)$

25 (16.6)

$18(11.9)$

$4(2.6)$

$3(2.0)$

86 (57.0)

$53(35.1)$

12 (7.9)

149 (98.7)

126 (83.4)

$14(9.3)$

$3(2-5)$

2 (1-3)
$55.3 \pm 10.3$

115 (76.2)

$36.7 \pm 11.8$

$21.0 \pm 10.3$

29 (19.2)

79 (52.3)

43 (28.5)

$53(35.1)$

106 (70.2)

70 (46.4)

26 (17.2)

$9(6.0)$

28 (18.5)

28 (18.5)

5 (3.3)

6 (4.0)

83 (55.0)

61 (40.4)

7 (4.6)

$148(98.0)$

129 (85.4)

4 (2.6)

3 (2-4)

2 (1-3) as necessary to obtain participant follow-up). Of these, only 1 participant had a carbon monoxide reading greater than $10 \mathrm{ppm}$ and was classified as having returned to smoking. Sensitivity analyses were conducted for smoking abstinence and reduction at weeks 4, 12, 24 and 52, which included only participants who returned for follow-up (in order to assess the effect of the assumption that participants who withdrew or were lost to follow-up returned to smoking at their baseline rate). These unadjusted analyses found similar differences in smoking abstinence and reduction end points (Appendix 1, supplementary Tables 1 and 2). 


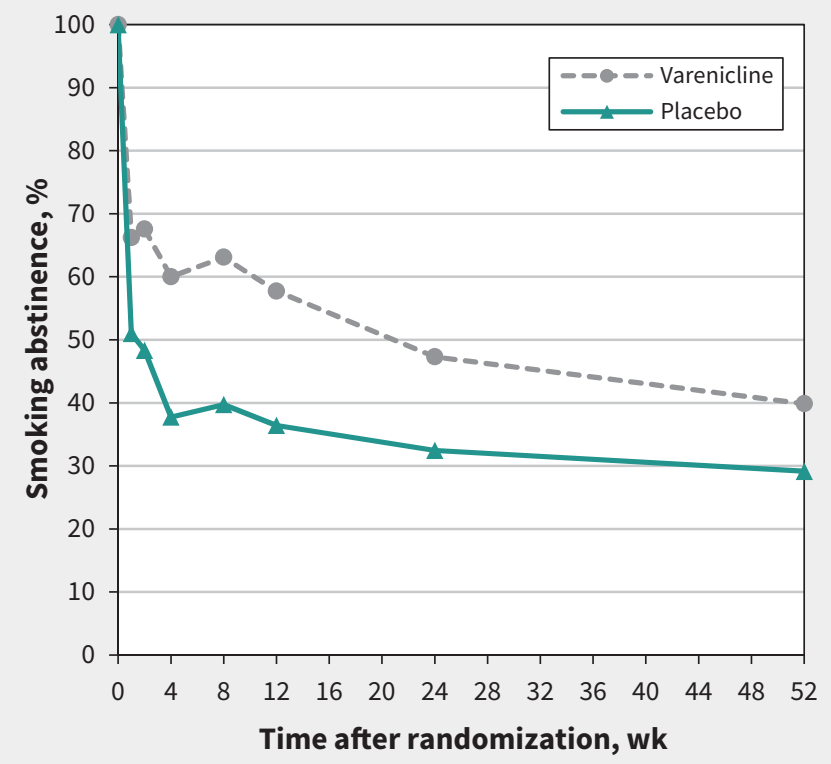

Figure 2: Trends in point-prevalence smoking abstinence from baseline to week 52. All analyses were intention-to-treat. Patients who withdrew consent or were lost to follow-up were assumed to have returned to smoking at their baseline rate. Participants who died were censored after the time of death. Participants were considered abstinent if they abstained from smoking in the 7 days before the visit through a selfreport of 0 cigarettes smoked per day, confirmed by exhaled carbon monoxide levels of $10 \mathrm{ppm}$ or less at clinic visits (available for $94.7 \%$, $87.3 \%, 79.7 \%$ and $81.7 \%$ of self-reported abstinent participants at weeks $4,12,24$ and 52 , respectively).

\section{Low-intensity counselling and nonstudy cessation therapies}

As part of the trial, participants received low-intensity counseling, with a mean of 51.4 (SD 33.5) minutes for all participants from baseline to week 52. Participants were also permitted to seek counselling outside of the study; however, only $2.7 \%$ of participants did so at any point (equal in each treatment arm). Following the 12-week treatment period, participants who had relapsed were also permitted to use nonstudy pharmacotherapy treatments for smoking cessation. Use of a nonstudy treatment at any point in the trial was $18.3 \%$ overall $(14.9 \%$ in the varenicline group v. $21.8 \%$ in the placebo group). Participants reported using (non-mutually exclusive categories): $6.6 \%$ e-cigarette, $6.0 \%$ nicotine patch, $4.3 \%$ short-acting nicotine replacement therapy (e.g., gum, inhaler or lozenge), $2.6 \%$ varenicline and $2.0 \%$ other.

\section{Safety}

The occurrence of serious adverse events was similar between trial arms (Table 2). Overall, there were 93 serious adverse events between baseline and week 52, occurring in 70 patients (37 in the treatment arm [24.5\%] and 33 in the placebo arm [21.9\%]). A total of 30 major adverse cardiovascular events were reported in 27 patients (13 in the treatment arm [8.6\%] and 14 in the placebo arm [9.3\%]), including 17 myocardial infarctions, 11 hospital admissions for unstable angina and 2 cardiovascular deaths ( 2 patients experienced both myocardial infarction and unstable angina, and 1 patient had 2 separate instances of unstable angina). Both deaths occurred within 30 days of treatment discontinuation in patients in the varenicline arm ( 1 because of congestive heart failure 40 days after randomization and 18 days after discontinuing study drug; the other due to sudden death 25 days after randomization in a patient presumed to have taken the study drug until the time of death). A single noncardiovascular death occurred in a patient in the varenicline arm due to a perforated ulcer 63 days after study drug discontinuation.

\section{Interpretation}

Use of varenicline significantly increased abstinence compared with placebo (39.9\% v. 29.1\%) 52 weeks after hospital admission for acute coronary syndrome. This finding is important given the substantial reduction in cardiovascular risk conferred by smoking cessation in this high-risk population. ${ }^{1,2,18,19}$ In addition, rates of serious adverse events (24.5\% v. $21.9 \%)$ and major adverse cardiovascular events ( $8.6 \%$ v. 9.3\%) were similar between varenicline and placebo arms. This suggests that varenicline is safe for use in these patients. However, new strategies for smoking cessation are still needed, given that $60 \%$ of smokers who received treatment with varenicline returned to smoking by 1 year after their acute coronary syndrome.

The use of varenicline in the EVITA trial differed in one significant way from the usual method of administration recommended. Typically, patients are instructed to begin taking the drug 8-14 days before a quit date to allow time for titration and bioaccumulation. ${ }^{20}$ In the EVITA trial, whereas the dose was titrated as recommended over 7 days, participants were already not smoking at the time of randomization (due to hospital admission) and were instructed not to resume smoking on discharge. This approach appears to have been efficacious, given that the differences between groups were apparent from week 1 , with only half of participants in the placebo arm abstinent (51.0\%) compared with two-thirds of participants in the varenicline arm (66.2\%). However, this approach could have resulted in increased "slips" (i.e., temporary lapses to smoking) early in the trial, limiting our ability to detect significant differences between groups in regard to continuous smoking abstinence.

Safety concerns related to neuropsychiatric events and cardiovascular events associated with the use of varenicline ${ }^{21-25}$ have largely been resolved, ${ }^{26-30}$ with high-quality evidence suggesting that varenicline is safe for use in both populations with prior psychiatric illness and history of cardiovascular disease. In particular, compelling evidence has been generated by the EAGLES trial ( $n=8144$ participants), ${ }^{31}$ which found no difference in the incidence of neuropsychiatric events between individuals (with or without psychiatric disease) receiving varenicline, bupropion, nicotine patch or placebo. There were very few serious cardiovascular adverse events reported, with no apparent differences between groups. Likewise, the CATS trial $(n=$ 4595 participants) found no difference in the incidence of major 


\section{A}

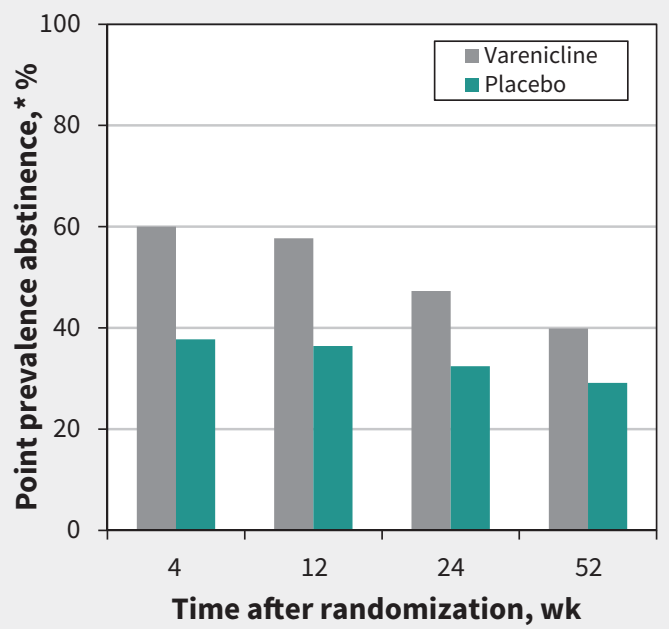

Time after randomization, wk
B

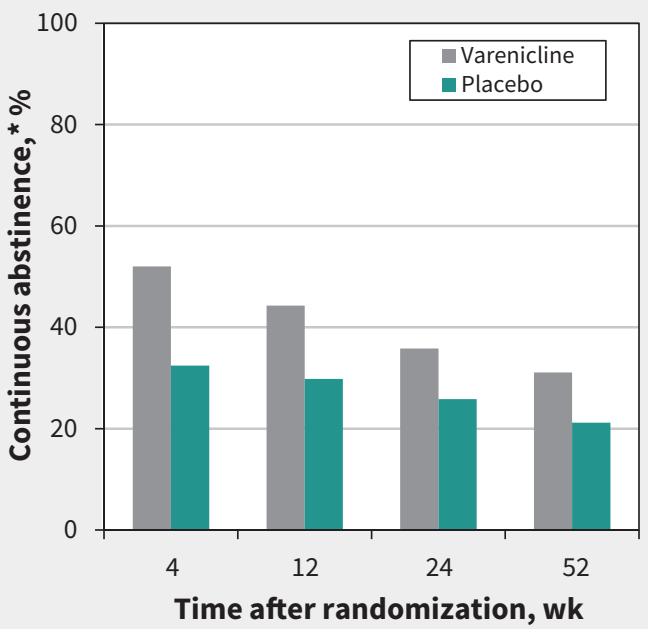

C

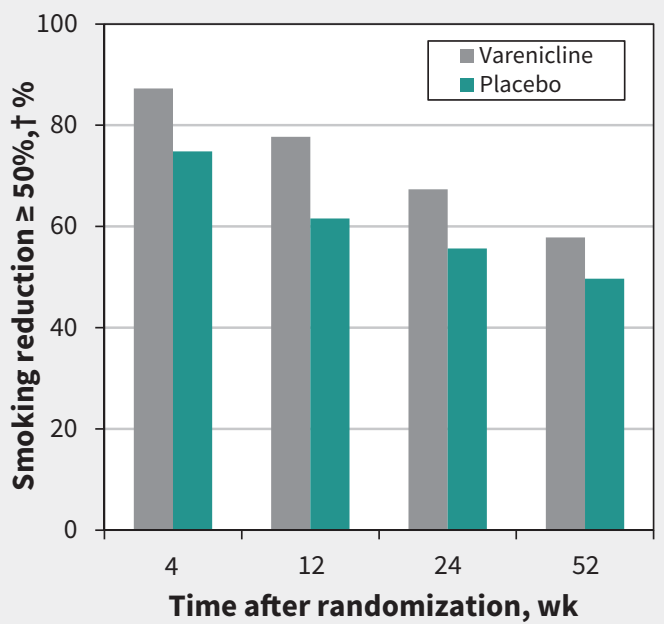

Figure 3: Smoking cessation and reduction by treatment group. All analyses were intention-to-treat. Participants who withdrew consent or were lost to follow-up were assumed to have returned to smoking at their baseline rate. Participants who died were censored after the time of death. A) Smoking cessation: point-prevalence abstinence. Participants were considered abstinent if they abstained from smoking in the 7 days before the visit through a self-report of 0 cigarettes smoked per day, confirmed by exhaled carbon monoxide levels of $10 \mathrm{ppm}$ or less (available for $94.7 \%, 87.3 \%, 79.7 \%$ and $81.7 \%$ of self-reported abstinent participants at weeks 4, 12, 24 and 52, respectively). Risk differences: 4 weeks, 22.3 (95\% confidence interval $[\mathrm{Cl}] 11.2$ to 33.3 ); 12 weeks, 21.3 (95\% Cl 10.3 to 32.3); 24 weeks, 14.9 (95\% Cl 3.9 to 25.8 ); 52 weeks, 10.7 (95\% Cl 0.01 to 21.4). B) Smoking cessation: continuous abstinence. Participants were considered abstinent if they abstained from smoking through a selfreport of 0 cigarettes smoked per day, confirmed by exhaled carbon monoxide levels of $10 \mathrm{ppm}$ or less (available for $96.9 \%, 91.0 \%, 82.6 \%$ and $88.5 \%$ of self-reported continuously abstinent participants at weeks $4,12,24$ and 52, respectively) at all follow-up visits. Risk differences: 4 weeks, 19.6 ( $95 \% \mathrm{Cl} 8.6$ to 30.5$)$ ); 12 weeks, 14.5 (95\% Cl 3.7 to 25.3$) ; 24$ weeks, 10.0 ( $95 \% \mathrm{Cl}-0.4$ to 20.4$)$; 52 weeks, 9.9 (95\% Cl -0.1 to 19.8$)$. C) Reduction in daily cigarette consumption of $50 \%$ or more from baseline; self-report only. Risk differences: 4 weeks, 12.4 (95\% Cl 3.7 to 21.2$)$; 12 weeks, 16.1 (95\% Cl 5.9 to 26.4$) ; 24$ weeks, 11.7 (95\% Cl 0.8 to 22.7$) ; 52$ weeks, 8.2 (95\% Cl -3.1 to 19.4). *Adjusted for loss to follow-up. †In self-reported daily cigarette consumption from baseline.

adverse cardiovascular events between the same groups. ${ }^{32}$ In addition, Sterling and colleagues conducted a meta-analysis of 38 randomized controlled trials ( $n=12706$ participants), which found no difference in serious cardiovascular adverse events when comparing varenicline with placebo in populations either with or without cardiovascular disease. ${ }^{33}$ Overall, evidence accu- mulated from these trials and meta-analyses provides strong support that use of varenicline is safe for smoking cessation.

\section{Limitations}

Our trial had several potential limitations. First, enrolment was restricted to patients with acute cardiovascular disease who 


\begin{tabular}{|c|c|c|c|}
\hline Serious adverse events from baseline to week 52 & $\begin{array}{c}\text { Varenicline } \\
n=151\end{array}$ & $\begin{array}{c}\text { Placebo } \\
n=151\end{array}$ & Risk difference $(95 \% \mathrm{Cl})$ \\
\hline Any serious adverse event ${ }^{\star}$ & $37(24.5) \dagger$ & $33(21.9) \ddagger$ & $2.7(-7.3$ to 12.6$)$ \\
\hline $\begin{array}{l}\text { Composite major adverse cardiovascular events } \\
\text { (cardiovascular death, MI, unstable angina) }\end{array}$ & $13(8.6)$ & $14(9.3)$ & $-0.7(-7.8$ to 6.5$)$ \\
\hline MI & $8(5.3)$ & $9(6.0)$ & $-0.7(-6.7$ to 5.4$)$ \\
\hline Unstable angina & $4(2.6)$ & $6(4.0)$ & $-1.3(-6.5$ to 3.7$)$ \\
\hline Other cardiovascular event & $6(4.0)$ & $3(2.0)$ & $2.0(-2.8$ to 7.1$)$ \\
\hline Noncardiovascular death & $1(0.7)$ & 0 & $0.7(-2.5$ to 4.2$)$ \\
\hline Other neuropsychiatric event & $1(0.7)$ & 0 & $0.7(-2.5$ to 4.2$)$ \\
\hline Other & $19(12.6)$ & $17(11.3)$ & $1.3(-6.6$ to 9.3$)$ \\
\hline \multicolumn{4}{|c|}{ 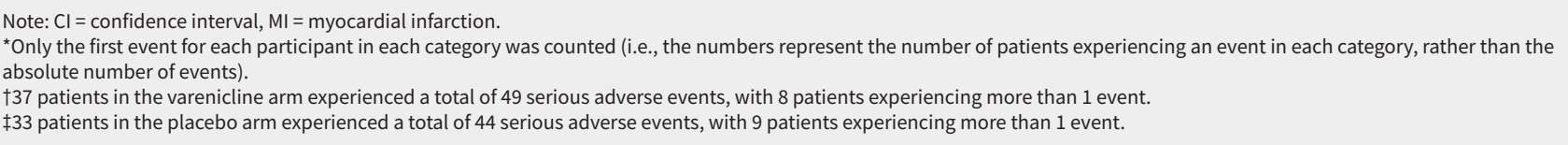 } \\
\hline
\end{tabular}

were motivated to quit smoking. Therefore, our findings may not be generalizable to patients with stable cardiovascular disease or to the general population of hospital-admitted smokers after acute coronary syndrome. Second, counselling provided to both groups was of low intensity, which may have reduced quit rates overall. However, our findings may represent a real-world scenario in which patients receive (or seek) little psychosocial intervention. Participants were encouraged to use additional counselling resources outside of the study, and only $2.7 \%$ did so at any point. Lastly, our findings may underestimate the efficacy of varenicline over time for several reasons. The first is that participants who had not successfully quit were permitted to use other smoking cessation therapies during trial follow-up. Given that $21.8 \%$ of participants in the placebo arm compared with $14.9 \%$ in the varenicline arm used other cessation therapies, this may have resulted in an underestimation of the efficacy of varenicline. Likewise, an imbalance in proportion of participants with another smoker living at home $(48.3 \%$ in the varenicline arm v. $35.1 \%$ in the placebo arm) may have resulted in increased relapse in the varenicline group.

\section{Conclusion}

We examined the efficacy of varenicline versus placebo, initiated in-hospital and in conjunction with low-intensity counselling, for smoking cessation 52 weeks after acute coronary syndrome. We found that varenicline is efficacious for smoking cessation; however, $60 \%$ of patients who received treatment with varenicline still returned to smoking by 1 year. If varenicline were used routinely after acute coronary syndrome, for every 10 smokers who received treatment there would be 1 less smoker a year later.

\section{References}

1. Critchley JA, Capewell S. Mortality risk reduction associated with smoking cessation in patients with coronary heart disease: a systematic review. JAMA 2003;290:86-97.

2. Colivicchi F, Mocini D, Tubaro M, et al. Effect of smoking relapse on outcome after acute coronary syndromes. Am J Cardiol 2011;108:804-8.

3. How tobacco smoking causes disease: the biology and behavioral basis for smoking-attributable disease: a report of the Surgeon General. Atlanta: US Department of Health and Human Services, Centers for Disease Control and Prevention, National Center for Chronic Disease Prevention and Health Promotion, Office on Smoking and Health; 2010.

4. The health consequences of smoking: a report of the Surgeon General. Atlanta: US Department of Health and Human Services, Centers for Disease Control and Prevention, National Center for Chronic Disease Prevention and Health Promotion, Office on Smoking and Health; 2004.

5. Dornelas EA, Sampson RA, Gray JF, et al. A randomized controlled trial of smoking cessation counseling after myocardial infarction. Prev Med 2000; 30:261-8.

6. Suissa K, Lariviere J, Eisenberg MJ, et al. Efficacy and safety of smoking cessation interventions in patients with cardiovascular disease: a network meta-analysis of randomized controlled trials. Circ Cardiovasc Qual Outcomes 2017 Jan;10. pii: e002458.

7. Eisenberg MJ, Blum LM, Filion KB, et al. The efficacy of smoking cessation therapies in cardiac patients: a meta-analysis of randomized controlled trials. Can J Cardiol 2010;26:73-9.

8. Eisenberg MJ, Grandi SM, Gervais A, et al. Bupropion for smoking cessation in patients hospitalized with acute myocardial infarction: a randomized, placebo-controlled trial. J Am Coll Cardiol 2013;61:524-32.

9. Rigotti NA, Thorndike AN, Regan S, et al. Bupropion for smokers hospitalized with acute cardiovascular disease. Am J Med 2006;119:1080-7.

10. Planer D, Lev I, Elitzur Y, et al. Bupropion for smoking cessation in patients with acute coronary syndrome. Arch Intern Med 2011;171:1055-60.

11. Cahill K, Stevens S, Perera R, et al. Pharmacological interventions for smoking cessation: an overview and network meta-analysis. Cochrane Database Syst Rev 2013;(5):CD009329.

12. Anthenelli RM, Benowitz NL, West R, et al. Neuropsychiatric safety and efficacy of varenicline, bupropion, and nicotine patch in smokers with and without psychiatric disorders (EAGLES): a double-blind, randomised, placebo-controlled clinical trial. Lancet 2016;387:2507-20. 
13. Cahill K, Lindson-Hawley N, Thomas KH, et al. Nicotine receptor partial agonists for smoking cessation. Cochrane Database Syst Rev 2016; (5):CD006103.

14. Eisenberg MJ, Windle SB, Roy N, et al. Varenicline for smoking cessation in hospitalized patients with acute coronary syndrome. Circulation 2016;133:21-30.

15. Windle SB, Bata I, Madan M, et al. A randomized controlled trial of the efficacy and safety of varenicline for smoking cessation after acute coronary syndrome: design and methods of the Evaluation of Varenicline in Smoking Cessation for Patients Post-Acute Coronary Syndrome trial. Am Heart J 2015;170:635-40.e1.

16. Ryter SW, Choi AMK. Carbon monoxide in exhaled breath testing and therapeutics. J Breath Res 2013;7:017111.

17. Grandi SM, Gervais A, Joseph L, et al. Assessment of the validity of self-report as a measure of smoking status in patients post-myocardial infarction. CJGIM 2014;9:137-9

18. Gerber Y, Rosen LJ, Goldbourt U, et al. Smoking status and long-term survival after first acute myocardial infarction a population-based cohort study. J Am Coll Cardiol 2009;54:2382-7.

19. Zhang YJ, Iqbal J, van Klaveren D, et al. Smoking is associated with adverse clinical outcomes in patients undergoing revascularization with $\mathrm{PCl}$ or CABG: the SYNTAX trial at 5-year follow-up. J Am Coll Cardiol 2015;65:1107-15.

20. Champix product monograph. Pfizer Canada; 2016. Available: www.pfizer.ca/ sites/g/files/g10028126/f/201610/CHAMPIX_PM_188898_60ct2016_E.pdf (accessed 2017 Nov. 22).

21. Singh S, Loke YK, Spangler JG, et al. Risk of serious adverse cardiovascular events associated with varenicline: a systematic review and meta-analysis. CMAJ 2011;183:1359-66.

22. FDA Drug Safety Communication: Chantix (varenicline) may increase the risk of certain cardiovascular adverse events in patients with cardiovascular disease. Silver Spring (MD): US Food and Drug Administration; 2011. Available: www. fda.gov/Drugs/DrugSafety/ucm330367.htm (accessed 2017 Nov. 22).

23. FDA Drug Safety Communication: Safety review update of Chantix (varenicline) and risk of cardiovascular adverse events. Silver Spring (MD): US Department of Health and Human Services; 2012. Available: www.fda.gov/Drugs/DrugSafety/ ucm330367.htm (accessed 2015 Aug. 30).
24. Public Health Advisory: FDA requires new boxed warnings for the smoking ces sation drugs Chantix and Zyban. Silver Spring (MD): US Department of Health and Human Services; 2009.

25. FDA Drug Safety Communication: Safety review update of Chantix (varenicline) and risk of neuropsychiatric adverse events. Silver Spring (MD): US Department of Health and Human Services; 2011. Available: www.fda.gov/Drugs/ DrugSafety/ucm276737.htm (accessed 2015 Mar. 6)

26. Prochaska JJ, Hilton JF. Risk of cardiovascular serious adverse events associated with varenicline use for tobacco cessation: systematic review and meta-analysis. BMJ 2012;344:e2856.

27. Ware JH, Vetrovec GW, Miller AB, et al. Cardiovascular safety of varenicline: patient-level meta-analysis of randomized, blinded, placebo-controlled trials. Am J Ther 2013;20:235-46.

28. Thomas KH, Martin RM, Knipe DW, et al. Risk of neuropsychiatric adverse events associated with varenicline: systematic review and meta-analysis. $B M J$ 2015;350:h1109.

29. Kotz D, Viechtbauer W, Simpson C, et al. Cardiovascular and neuropsychiatric risks of varenicline: a retrospective cohort study. Lancet Respir Med 2015; 3:761-8.

30. Mills EJ, Thorlund K, Eapen S, et al. Cardiovascular events associated with smoking cessation pharmacotherapies: a network meta-analysis. Circulation 2014;129:28-41.

31. Pfizer. Study evaluating the safety and efficacy of varenicline and bupropion for smoking cessation in subjects with and without a history of psychiatric disorders (EAGLES) ClinicalTrials.gov: NCT01456936; [updated 2016]. Available: www.clinicaltrials.gov/ct2/show/NCT01456936 (accessed 2016 Nov. 10).

32. Pfizer. Study to evaluate cardiac assessments following different treatments of smoking cessation medications in subjects with and without psychiatric disorders (CATS). ClinicalTrials.gov: NCT01574703; [updated 2016]. Available: https://clinicaltrials.gov/ct2/show/NCT01574703 (accessed 2017 Oct. 23).

33. Sterling LH, Windle SB, Filion KB, et al. Varenicline and adverse cardiovascular events: a systematic review and meta-analysis of randomized controlled trials. J Am Heart Assoc 2016;5: pii: e002849.

\begin{abstract}
Competing interests: Shamir Mehta reports funding from AstraZeneca, Boston Scientific, Bayer and Abbott. Beth Abramson has received grants or research support from AstraZeneca and Sanofi; honoraria from Amgen, AstraZeneca, Boehringer Ingelheim, Bristol-Myers Squibb, Novartis, Fournier, Merck, Pfizer, Servier and Sanofi; and consulting fees from Amgen, Bayer, Boehringer Ingelheim, Sanofi and Servier. She authored Heart Health for Canadians. Mark Eisenberg, Payam Dehghani, François-Grondin and Mina Madan received honoraria from Pfizer for providing continuing medical education on smoking cessation. No other competing interests were declared
\end{abstract}

\section{This article has been peer reviewed.}

Affiliations: Jewish General Hospital, McGill University (Windle, Eisenberg), Montréal, Que.; Prairie Vascular Research Network (Dehghani), University of Saskatchewan, Regina, Sask.; Centre de santé et de services sociaux de Chicoutimi (Roy), Chicoutimi, Que.; Sentara Cardiovascular Research Institute (Old), Norfolk, Va.; Centre intégré de santé et de services sociaux Chaudière-Appalaches (Grondin), Hôtel-Dieu de Lévis site, Lévis, Que.; Queen Elizabeth II Health Sciences Centre (Bata),
Halifax, NS; SJH Cardiology Associates and St. Joseph's Hospital Health Centre (Iskander), Liverpool, NY; Centre intégré de santé et de services sociaux Chaudière-Appalaches (Lauzon), Hôpital de Saint-Georges site, Thetford Mines, Que.; Spartanburg Regional Medical Center (Srivastava), Spartanburg, SC; Valley Regional Hospital (Clarke), Kentville, NS; Toledo Hospital (Cassavar), Toledo, Ohio; Centre de santé et de services sociaux de Beauce (Dion), Beauce, Que.; Heart Center Research (Haught), Huntsville, Ala.; McMaster University and Hamilton Health Sciences (Mehta), Hamilton, Ont.; Dr. Georges-L.Dumont University Hospital Centre (Baril), Moncton, NB; Florida Hospital Pepin Heart Institute (Lambert), Tampa, Fla.; Sunnybrook Health Sciences Centre (Madan), University of Toronto, Toronto, Ont.; St. Michael's Hospital (Abramson), Toronto, Ont.

Contributors: The steering committee, comprising Mark Eisenberg (Chair), Beth Abramson, Iqbal Bata and Mina Madan, made substantial contributions to the conception or design of the work. All of the authors made substantial contributions to the acquisition, analysis or interpretation of data. Sarah Windle drafted the article, and all remaining authors revised it critically for important intellectual content. All of the authors gave final approval of the version to be published and agreed to be accountable for all aspects of the work.

${ }^{*}$ A complete list of EVITA Investigators is provided in Appendix 1, available at www.cmaj.ca/ lookup/suppl/doi:10.1503/cmaj.170377/-/DC1.

Funding: EVITA was an investigator-initiated trial that received funding and the study drug and placebo from Pfizer Inc. Pfizer had no role in the design, conduct, analysis, interpretation of data, or reporting of the EVITA trial.

Acknowledgements: The authors' thanks go to the patients across North America who participated in the EVITA trial, as well as the research teams who conducted enrolment and follow-up. The authors additionally thank Joseph Mancini, Natalie Zacchia, and Bettina Habib for their assistance with trial coordination and data management, as well as Patrick Bélisle for his help with data analysis.

\section{Accepted: Nov. 28, 2017}

Correspondence to: Mark Eisenberg, mark. eisenberg@mcgill.ca 